\title{
Covid-19: death rate is $0.66 \%$ and increases with age, study estimates
}

\author{
Elisabeth Mahase
}

The BMJ

The overall death rate from covid- 19 has been estimated at $0.66 \%$, rising sharply to $7.8 \%$ in people aged over 80 and declining to $0.0016 \%$ in children aged 9 and under. ${ }^{1}$

The estimates, calculated by researchers in the UK, used aggregate data on cases and deaths in mainland China. Unlike other estimates, however, they adjusted for undiagnosed cases and the number of people in each age group of a population.

The team found that nearly one in five people over 80 infected with covid-19 would probably require hospital admission, compared with around $1 \%$ of people under 30 .

They also estimated that the average time between a person displaying symptoms and dying was 17.8 days, while recovering from the disease was estimated to take slightly longer, with patients being discharged from hospital after an average of 22.6 days.

The paper, published in the Lancet Infectious Diseases and funded by the UK Medical Research Council, analysed data from 3665 covid-19 cases in mainland China to estimate the admission rate among different age groups.

It reported that $0.04 \%$ of $10-19$ year olds would probably require hospital care-as would $1.0 \%$ of people in their $20 \mathrm{~s}, 3.4 \%$ of people aged $30-39,4.3 \%$ aged $40-49,8.2 \%$ aged $50-59,11.8 \%$ in their $60 \mathrm{~s}, 16.6 \%$ in their $70 \mathrm{~s}$, and $18.4 \%$ of those over 80 .

\section{Infection fatality ratio}

Neil Ferguson, lead researcher from Imperial College London who carries out modelling for the UK government's covid-19 response, said, "As the UK epidemic unfolds, more data are becoming available, and at the moment the proportion of people in each age group most likely to require hospitalisation and [the proportion] most likely to die from infection are consistent with the estimates in this study."

For the case fatality rate the team analysed 70117 laboratory confirmed and clinically diagnosed cases in mainland China, along with 689 positive cases among people evacuated from Wuhan on repatriation flights.

Using the number of confirmed cases and deaths, the researchers reported the "crude case fatality ratio" as $3.67 \%$ (95\% confidence interval $3.56 \%$ to $3.80 \%$ ). However, after adjusting for demography and under-ascertainment, they estimated the case fatality ratio (the percentage of people with symptomatic or confirmed disease who die from the disease) in China as $1.38 \%$ ( $1.23 \%$ to $1.53 \%)$.

They then estimated the infection fatality ratio (the percentage of all infected people who die from the disease, including those with mild disease) as $0.66 \%$ ( $0.39 \%$ to $1.33 \%)$.

\section{Healthcare systems overwhelmed}

The team warned in their paper, "Our estimate of the proportion of infected individuals requiring hospitalisation, when combined with likely infection attack rates (around 50-80\%), show that even the most advanced healthcare systems are likely to be overwhelmed. These estimates are therefore crucial to enable countries around the world to best prepare as the global pandemic continues to unfold."

The paper had some limitations, including the researchers being unable to adjust for the effect on prognosis of underlying health conditions owing to a lack of individual level data.

The research team reported no competing interests, but they reported receiving grants from the World Health Organization; Gavi, the Vaccine Alliance; Janssen Pharmaceuticals; and the Bill and Melinda Gates Foundation, for work outside of this study.

1 Verity R, Okell LC, Dorigatti I, et al. Estimates of the severity of coronavirus disease 2019 a model-based analysis. Lancet Infect Dis 2020 Mar 30. https://www.thelancet.com journals/laninf/article/PIIS1473-3099(20)30243-7/fulltext.

Published by the BMJ Publishing Group Limited. For permission to use (where not already granted under a licence) please go to http://group.bmj.com/group/rights-licensing/ permissions 